Western University

Scholarship@Western

Mechanical and Materials Engineering

Mechanical and Materials Engineering

Publications

Department

2018

\title{
Numerical Modeling and Control of Solids Separation Using Continuously Moving Fine Mesh Filters
}

Anthony Sherratt

Western University, asherra@uwo.ca

Christopher T. DeGroot

Western University, cdegroo5@uwo.ca

Anthony G. Straatman

uwo, agstraat@uwo.ca

Domenico Santoro

USP Technologies, dsantoro@usptechnologies.com

Follow this and additional works at: https://ir.lib.uwo.ca/mechanicalpub

Part of the Materials Science and Engineering Commons, and the Mechanical Engineering Commons

\section{Citation of this paper:}

Sherratt, Anthony; DeGroot, Christopher T.; Straatman, Anthony G.; and Santoro, Domenico, "Numerical Modeling and Control of Solids Separation Using Continuously Moving Fine Mesh Filters" (2018).

Mechanical and Materials Engineering Publications. 7.

https://ir.lib.uwo.ca/mechanicalpub/7 


\title{
Numerical modeling and control of solids separation using continuously moving fine mesh filters
}

\author{
Anthony Sherratt ${ }^{\mathrm{a}}$, Christopher T. DeGroot ${ }^{\mathrm{a}, *}$, Anthony G. Straatman ${ }^{\mathrm{a}}$, Domenico Santoro ${ }^{\mathrm{b}}$ \\ ${ }^{a}$ Department of Mechanical and Materials Engineering, University of Western Ontario, London, Ontario, Canada \\ ${ }^{\mathrm{b}}$ Trojan Technologies, 3020 Gore Road, London, Ontario, Canada
}

\section{H I G H L I G H T S}

- Cake resistance can be measured by drainage column with continuous level monitoring.

- Cake resistance can be scaled based on suspended solids in influent sample.

- A PID controller can maintain water level when suspended solids concentration varies.

- A one-dimensional process model can accurately predict filter performance.

\section{A R T I C L E I N F O}

\section{Article history:}

Received 19 July 2018

Received in revised form 22 September

2018

Accepted 22 October 2018

Available online 24 October 2018

\section{Keywords:}

Filtration

Primary wastewater treatment

Solids separation

Control
G R A P H I C A L A B S T R A C T

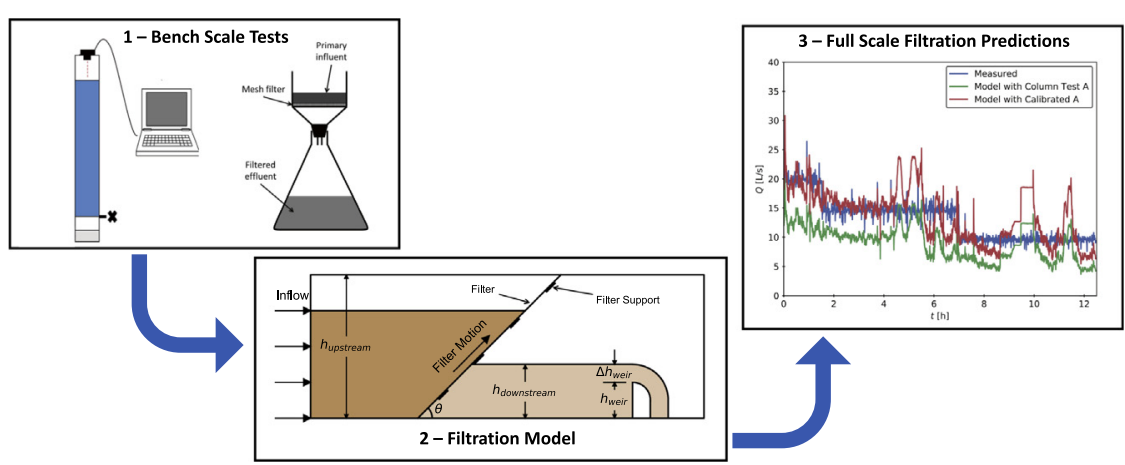

\begin{abstract}
A B S T R A C T
This work presents a numerical model for solids separation using continuously moving, inclined fine mesh filters. One of the main difficulties in modeling fine mesh filters is the characterization of the cake resistance as the solids accumulate on the filter. It is proposed to model the cake resistance using a gravity drainage column experiment implementing continuous water level monitoring. Based on the drainage curve, an analytical formulation is developed for the cake resistance, as a function of the filtered volume per unit area, $V$. The removal efficiency is also correlated with $V$ through a sieve test. With the cake resistance and removal efficiency functions determined, a one-dimensional filter model is developed. Since the total suspended solids concentration varies as a function of time, and will not always be the same as that tested, a technique of scaling the cake resistance is introduced. A PID control algorithm is also developed into the model, so that the filter rotation speed can be controlled to maintain a set water level upstream of the filter. Results for sizing curves are given, as well as results for the PID controller operation, and validation results based on full-scale pilot testing.
\end{abstract}

(c) 2018 Elsevier Ltd. All rights reserved.

\section{Introduction}

Increasing population size and urban expansion has placed increased pressure on wastewater treatment plants (WWTPs) to achieve their effluent quality targets (Teklehaimanot et al., 2015).

\footnotetext{
* Corresponding author.

E-mail address: cdegroo5@uwo.ca (C.T. DeGroot).
}

Typical WWTPs implement multiple treatment stages including primary treatment, to remove readily settleable solids, and secondary treatment, to oxidize biodegradable matter and remove nutrients (Tchobanoglous et al., 2014). For primary treatment of wastewater, primary clarifiers (PCs) are most commonly used to remove solids based on the principle of gravity separation (Tchobanoglous et al., 2014). Sedimentation tanks are most commonly rectangular (typical length of $24-40 \mathrm{~m}$ and width of 


\section{Nomenclature}

a, mesh resistance coefficient, $\mathrm{m}^{-1}$

A, column test model parameter, $\mathrm{m}$

b, mesh resistance coefficient, $\mathrm{s} / \mathrm{m}^{2}$

$C_{T S S_{\text {in }}}$, concentration of influent total suspended solids, $\mathrm{mg} / \mathrm{L}$

$C_{T S S_{\text {out }}}$, concentration of effluent total suspended solids, $\mathrm{mg} / \mathrm{L}$

$C_{0}, \quad$ sieve test model parameter, $\mathrm{mg} / \mathrm{L}$

$e, \quad$ error between set point and process variable

$f$, open area fraction due to structural blockage, dimensionless

g, gravitational acceleration, $\mathrm{m} / \mathrm{s}^{2}$

$h$ vertical distance, $m$

$h_{\text {downstream }}$, downstream water level, $\mathrm{m}$

$h_{\text {upstream, }}$ upstream water level, $\mathrm{m}$

$h_{\text {weir }}$ downstream weir level, $m$

$\Delta h_{\text {weir }}, \quad$ level of water above downstream weir, $m$

$h_{0}$, initial column water level, m

$k_{P}$, $\quad$ proportional gain for PID controller

$k_{I}, \quad$ integral gain for PID controller

$k_{D}, \quad$ derivative gain for PID controller

$\Delta p, \quad$ pressure difference, $\mathrm{Pa}$
Q $\quad$ flow rate, $\mathrm{L} / \mathrm{s}$ or $\mathrm{m}^{3} / \mathrm{s}$

$R_{\text {cake }}, \quad$ cake resistance, $\mathrm{m}^{-1}$

$R_{\text {mesh }}, \quad$ mesh resistance, $\mathrm{m}^{-1}$

$R_{T}, \quad$ total resistance, $\mathrm{m}^{-1}$

$t, \quad$ time, $s$

$u$, control signal

$U$, bulk flow speed, $\mathrm{m} / \mathrm{s}$

$V, \quad$ filtered volume per unit area, $\mathrm{m}^{3} / \mathrm{m}^{2}$

$w$, filter width, $\mathrm{m}$

$\Delta x, \quad$ filter element size, $\mathrm{m}$

\section{Greek}

$\alpha, \quad$ column test model parameter, $\mathrm{s}^{-1}$

$\beta, \quad$ column test model parameter, $\mathrm{s}^{-1}$

$\gamma, \quad$ sieve test model parameter, $\mathrm{m}^{2} / \mathrm{m}^{3}$

$\eta$, solids removal efficiency, \%

$\theta, \quad$ angle of filter with respect to horizontal, ${ }^{\circ}$

$\mu$, dynamic viscosity, Pa.s

$\rho, \quad$ density, $\mathrm{kg} / \mathrm{m}^{3}$
5-10 m) or circular (typical diameter of 12-45 m) with a common depth of $4.3 \mathrm{~m}$ (Tchobanoglous et al., 2014). While a well-designed clarifier can remove $50-70 \%$ of total suspended solids (TSS) and $25-40 \%$ of biological oxygen demand (BOD) (Tchobanoglous et al., 2014), they occupy a large footprint and require a large capital investment to construct. Furthermore, it may be the case that a particular particle size distribution is experienced where target removal efficiencies cannot be attained by sedimentation (Rusten and Odegaard, 2006). In such cases, chemically enhanced primary treatment is required, which incurs an increased cost due to the chemicals required, and produces a larger volume of sludge (Rusten and Odegaard, 2006). As a result, there is an interest in developing new high-rate processes for primary solids separation that are more adaptable to varying influent conditions and have a smaller spatial footprint.

Fine mesh filters offer a potential alternative that can either replace or augment PCs in WWTPs. Stationary filters, as well as rotating drum, disc, and belt filters have been tested (Rusten and Odegaard, 2006). Based on the data of Rusten and Odegaard (2006), rotating belt filters appear to have the greatest potential, since they were able to meet all EU primary treatment guidelines in their study. Other benefits of fine mesh filtration that have been claimed include increased sludge energy potential (Paulsrud et al., 2014; Behera et al., 2018) and reduced aeration energy demand due to decreased solids loading (Franchi and Santoro, 2015; Behera et al., 2018). Chemical enhancement can also be applied to fine mesh filtration processes to further increase solids removal (Rusten and Odegaard, 2006; Franchi and Santoro, 2015; Rusten et al., 2017). It has been noted that removal performance is highly correlated with the influent TSS and the filter movement speed (Franchi and Santoro, 2015; Rusten et al., 2017).

In a system where the mesh filter is rotating, and continuously cleaned with each cycle, there are two main filtration modes that occur. When the clean filter comes into contact with the wastewater, solids greater than the mesh pore size are screened from the influent (Franchi and Santoro, 2015; DeGroot et al., 2015, 2016; Rusten et al., 2017). As a cake layer is accumulated on the filter, solids up to three times smaller than the mesh pore size can be removed due to the cake layer acting as a filter with a smaller pore size (Tien, 2012). In commercially available belt filter systems, the speed of rotation is typically controlled to modulate the cake thickness such that the treatment objectives are attained (Franchi and
Santoro, 2015; DeGroot et al., 2015, 2016). A slower rotation speed will result in a thicker cake layer, which yields higher TSS removal and lower hydraulic capacity. A higher rotation speed leads to a thinner cake layer, resulting in lower TSS removal with higher hydraulic capacity. This complex coupling between solids removal and hydrodynamics leads to difficulties in developing accurate models to predict filtration performance.

DeGroot et al. $(2015,2016)$ have developed process models for mesh filtration, including coupling with computational fluid dynamics for characterization of the hydrodynamics, based on the cake mass as the state variable determining cake resistance and TSS removal. Despite having a complete mathematical model developed, it has proven difficult to experimentally measure and correlate cake mass with the required operational parameters. Numerous mathematical models have been presented that characterize the resistance of mesh and cake layers, which show that the cake resistance is related to the cake porosity, particle density, particle diameter, and cake solidity (Bai and Tien, 2005; Tien and Ramarao, 2008, 2011; Tien, 2002; Teoh et al., 2006; Tien and Bai, 2003; Tien et al., 2014; Osterroth et al., 2016; Ho and Zydney, 2000). These models, however, have been developed primarily for the limits of constant flow rate or constant pressure differential, which are not applicable to inclined rotating filters which have spatially varying head differences and cake resistances. Most of the available models also assume that the mesh resistance does not depend on flow velocity, according to Darcy's law. This is only valid for very low pore Reynolds numbers, which are exceeded in the sieving region where a significant cake layer has not been developed. Therefore, the mesh resistance should be considered to be linearly varying with flow velocity, according to the DarcyForchheimer equation (Ward, 1964; Vafai and Tien, 1981).

Rusten and Odegaard (2006) proposed an experimental method for characterizing the removal efficiency and hydraulic capacity of a mesh sieve using a gravity drainage column test. In their experiment, a cylindrical pipe holds a known volume of water above a valve which controls the flow of wastewater through a mesh filter insert below. The valve is then opened and the wastewater, with a known TSS concentration, is allowed to flow through the filter. The effluent wastewater is then tested to determine the concentration of TSS from which the removal efficiency can be determined. The amount of time passed during the experiment is then used to calculate the hydraulic capacity, for a given influent TSS concentration. This 
experimental method did not, however, enable the instantaneous state of the filter to be correlated with the flow resistance and removal efficiency, which would be required to use a spatially discretized model of the form proposed by DeGroot et al. $(2015,2016)$.

The present study proposes a method that can efficiently and accurately model the resistance of a fine mesh filter with a cake layer using a gravity drainage column test with continuous water level monitoring. By monitoring the water level, the instantaneous hydrostatic pressure force and flow rates experienced by the filter become known. A variable-volume sieve test is also proposed to determine the removal efficiency as a function of the filtrate volume. The filtration model can then be used to develop a comprehensive model of a fine mesh filtration system with a continuously moving, inclined filter and to conduct parametric studies on its performance. Additionally, different control schemes can be modeled and tested to ensure that the filter unit responds properly to varying inlet conditions.

The outline for this article is as follows. First, the materials and methods will be presented, which includes the theoretical basis for the filtration model, as well as detailed descriptions of the gravity drainage and sieve tests. This section also includes a description of the model for continuously moving inclined filter systems, including scaling for varying TSS concentrations, and the controller implementation. Next, results will be presented for column and sieve test experiments as well as model results for the continuously moving inclined filter under varying TSS conditions. The control scheme is also tested to ensure that the water level can be accurately controlled while the influent TSS varies. Finally, the sensitivity of the model to its input parameters is studied and a calibration procedure is demonstrated to improve agreement with full-scale pilot results.

\section{Materials and methods}

\subsection{Theory}

The pressure drop across a porous medium is described by Darcy's law, given generally as

$\Delta p=\mu U R_{T}$

where $\Delta p$ is the pressure differential across the medium, $\mu$ is the dynamic viscosity of the fluid, $U$ is the bulk flow velocity, and $R_{T}$ is the total resistance coefficient.

For the purposes of this work, the resistance formulation is implemented rather than another approach based on the concept of permeability, since it easily allows for series resistances to be applied to account for the mesh and cake layers separately. By separating the mesh and cake resistances, it becomes possible to model the effects of changing influent TSS through appropriate scaling of the cake resistance, while leaving the mesh resistance as a linear function of velocity. The issue of scaling for TSS variations will be considered in more detail later. The mesh resistance is considered to be a function of flow velocity to account for the effects of pore-scale form drag at pore Reynolds numbers $R e_{d}>1$. Accordingly, the total resistance is written as two resistances in series, due to the mesh and cake layers, which is expressed as

$R_{T}=R_{\text {mesh }}+R_{\text {cake }}=(a+b U)+R_{\text {cake }}$

where $a$ and $b$ are the resistance coefficients describing the cake resistance as a linear function of flow velocity. For this work, values of $a=30,900 \mathrm{~m}^{-1}$ and $b=3,634,000 \mathrm{~s} / \mathrm{m}^{2}$ are used, which have been measured for a mesh filter with a nominal $350 \mu \mathrm{m}$ pore size (Sherratt et al., 2018).

\subsection{Gravity drainage column test}

A gravity drainage column test, shown schematically in Fig. 1, is used to determine the cake resistance as a function of cumulative filtered volume per unit area, assuming that the mesh resistance coefficients are known. The mesh resistance coefficients can be determined for a given case by relatively simple pressure drop experiments, or using computational fluid dynamics simulations (Sherratt et al., 2018). The experiment is performed by first transferring a known volume of water into the column, with the valve closed. The initial water level is typically chosen within the range of $70-110 \mathrm{~cm}$ to ensure that there are sufficient solids in the wastewater to build a cake layer. The diameter of the column used in this study is nominally 2 inches. Once filled, a knife valve located between the influent water and the clean filter is opened and the wastewater is allowed to flow through the filter insert. During the experiment, an ultrasonic level sensor records the water level. After all the water has passed through the filter or the flow rate is reduced to a negligible amount, the experiment is considered complete.

It has been observed that the column water height follows a double exponential relationship with respect to time, given as

$h(t)=A e^{-\alpha t}+\left(h_{0}-A\right) e^{-\beta t}$

where $A, \alpha$, and $\beta$ are model constants, while $h_{0}$ is the water level at time $t=0$. The form of the equation is chosen to constrain the model in such a way that $h(t=0)=h_{0}$. The model constants are obtained by fitting experimental column drainage data to Eq. (3). The double exponential function can be interpreted to represent the sum of two sources of resistance; the first term corresponding to the mesh dominated resistance and the second corresponding to cake dominated resistance, with a transition region in between. Since the experimental data is fitted to a curve, the equation to be manipulated analytically to solve for the parameters of interest, namely the flow velocity, cake resistance, and the cumulative filtered volume per unit area.

The fluid velocity is calculated analytically by differentiating Eq. (3) with respect to time, which results in

$U(t)=-\frac{d h}{d t}=A \alpha e^{-\alpha t}+\left(h_{0}-A\right) \beta e^{-\beta t}$

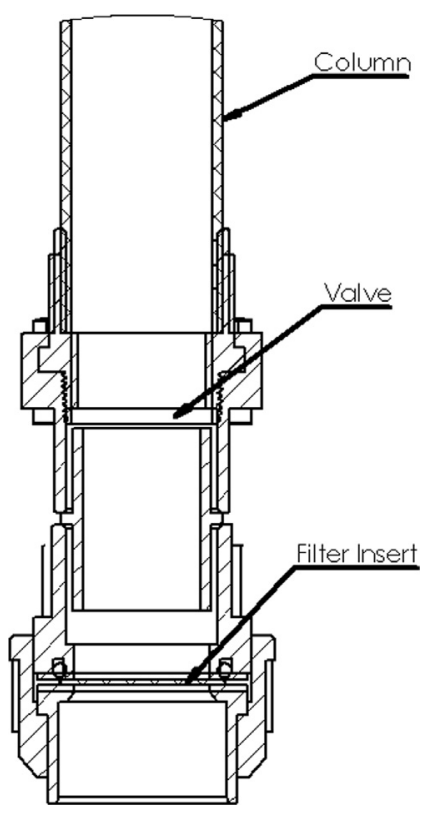

Fig. 1. Schematic diagram of the gravity drainage column test apparatus. 
An expression for the cake resistance is derived by combining Eqs. (1) and (2) and noting that the pressure difference across the filter is equal to the instantaneous hydrostatic head of the water column, i.e. $\Delta p(t)=\rho g h(t)$. This results in the expression

$R_{\text {cake }}(t)=\frac{\rho g h(t)}{\mu U(t)}-R_{\text {mesh }}(t)$

It is important to note the time dependencies indicated in Eq. (5). The water level as a function of time, $h(t)$, is obtained from Eq. (3), and the flow velocity as a function of time $U(t)$, is obtained from Eq. (4). The mesh resistance as a function of time is calculated as $R_{\text {mesh }}(t)=a+b U(t)$, where the resistance coefficients are constants and the time-dependency is due to the implicit dependence on $U(t)$.

The cumulative filtered volume per unit area is calculated by integrating the flow rate per unit area (i.e. the flow velocity) through the filter, with respect to time, which results in

$V(t)=A\left[1-e^{-\alpha t}\right]+\left(h_{0}-A\right)\left[1-e^{-\beta t}\right]$

The cake resistance can then be correlated with a specific cumulative filtered volume per unit area through Eqs. (5) and (6), with time being the parametric variable relating the two functions.

\subsection{Sieve test}

A sieve test is used to understand the relationship between removal efficiency and the state of the cake layer. To perform the sieve test, a known volume of water, with a known TSS concentration, is poured over a filter, and the effluent is collected. The TSS concentration of both the influent and effluent wastewater is measured using a gravimetric method. The experiment is then repeated for increasing volumes of water. The TSS concentration in the effluent is modeled using an exponential function of the cumulative filtered volume per unit area, of the form

$C_{\text {TSS }_{\text {out }}}=C_{0} e^{-\gamma V}$

where $C_{T S S_{\text {out }}}$ is the effluent concentration of TSS, while $C_{0}$ and $\gamma$ are model constants that are obtained by fitting Eq. (7) to sieve test data. Note that $C_{0}$ is not equal to the influent TSS concentration, $C_{T S S_{i n}}$, since the mesh is able to remove a certain portion of the TSS even before a cake layer is formed. The parameter $C_{0}$ is, however, a function of $C_{T S S_{\text {in }}}$.

\subsection{Process model for continuously moving inclined filters}

A schematic of the continuously moving inclined filter that is modeled in this study is shown in Fig. 2. Influent wastewater enters the domain to the left of the filter, at a height of $h_{\text {upstream }}$. The wastewater then flows through the filter due to gravity. The filter is inclined at an angle, $\theta$, from the horizontal, and the filter moves along this direction. In reality, the filter runs in a continuous loop, being cleaned with each revolution. In this model, only the portion of the filter that actively participates in removing solids is considered, as shown in Fig. 2. On the downstream side of the filter, the water level is $h_{\text {downstream }}$, which is dictated by the height of the downstream weir, $h_{\text {weir }}$, and the flow rate through the filter unit.

The filter is modeled in one spatial dimension, directed along the filter, and the driving force causing the fluid to flow through the filter is considered to be only due to the hydrostatic pressure difference across a given filter element. To solve the filtration problem, the spatial domain is discretized into $N$ uniform elements of size $\Delta x$, upon which the filtration model is applied. The spatial elements are taken to be fixed in space, and the application of the model over a particular element considers the change in filter conditions as the filter passes through the discrete space covered by the element.

To accommodate the fact that the filter may require support structure that would interfere with flow through the filter, such as that shown in Fig. 2, the model includes the option to block flow in certain regions as a function of their position along the axis of the filter. The open area ratio, $f$, varies from 0 to 1 , where 0 corresponds to the entire element being blocked by the support structure and 1 corresponds to no blockage. Since the support structure may also cover only a part of a particular element, the value of $f$ can also take on intermediate values between 0 and 1 corresponding to the fraction of the element that is open to flow.

The difference in hydrostatic pressure across each element is calculated based on the difference in head, $\Delta h$, from the upstream to downstream side of the filter. The head difference for the segment $i$, where $i$ ranges from 1 to $N$, is given as

$\Delta h_{i}= \begin{cases}h_{\text {upstream }}-h_{\text {downstream }} & \text { if } h_{i}<h_{\text {downstream }} \\ h_{\text {upstream }}-h_{i} & \text { if } h_{i} \geqslant h_{\text {downstream }}\end{cases}$

where $h_{i}$ is the vertical distance from the origin of the filter to the centroid of the element $i$. The downstream water height, $h_{\text {downstream }}$ is the sum of the weir height and the height of water above the weir, $\Delta h_{\text {weir, shown as }}$

$h_{\text {downstream }}=h_{\text {weir }}+\Delta h_{\text {weir }}$

The height of water above the weir is calculated based on the correlation

$\Delta h_{\text {weir }}=\left[\frac{Q / w}{3800}\right]^{2 / 3}$

where $Q / w$ is the instantaneous flow rate through the system, per unit width. This correlation was obtained using computational fluid dynamics simulations of flow over a weir at an angle of $30^{\circ}$ to the horizontal. This angle was selected to match with the filter angles considered in this study. When initializing the head difference,

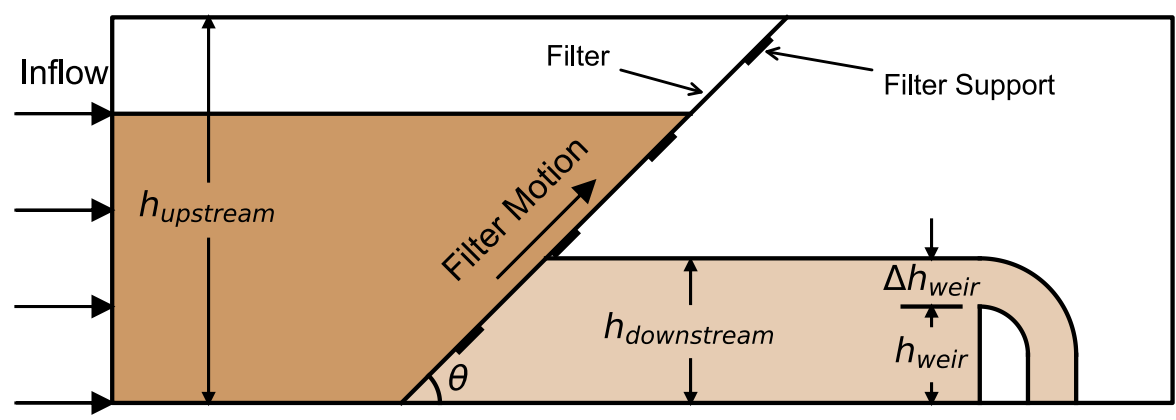

Fig. 2. Schematic diagram of a generic moving inclined filter. 
the flow rate through the system is set to zero, and the system is iteratively converged to a steady-state solution.

Within the main calculation loop, the fluid velocity through each element along the filter is calculated by solving Eq. (5) for the velocity, $U$. The head difference for this equation is given by Eq. (8), and the mesh resistance is expressed using the resistance coefficients as $R_{\text {mesh }}=a+b U$. This results in a quadratic equation for $U$, which has the solution for a particular element $i$ that is given by

$U_{i}=\frac{-\left(a+R_{\text {cake }}\right)+\sqrt{\left(a+R_{\text {cake }}\right)^{2}+4 b \rho g \Delta h / \mu}}{2 b}$

where the positive root is taken from the quadratic formula, since the negative root is guaranteed to produce a negative velocity, which is not physically correct. For the first element, the cake resistance is assumed to be zero, which is representative of the fact that the filter is cleaned after each rotation. At each subsequent filter element, the value of the cake resistance is taken from that at the previous element, since this represents the condition of the filter at the time that it arrives to the given element location.

The cake resistance is calculated based on data obtained from column tests. Since the relationship between cake resistance and cumulative filtered volume per unit area is generally too complex to model with a simple functional relationship, a look up table approach has been implemented. As such, the results of Eqs. (5) and (6) are tabulated over a suitably long time interval such that the cake resistance for a particular element can be linearly interpolated from the tabulated data, based on the cumulative filtered volume per unit area at that location.

For the interpolation of cake resistance, the total amount of volume per unit area that is filtered up until a given point on the filter must be tracked. For a given element, the amount of filtrate that passes through, during the time that it takes for the filter to move a distance equal to $\Delta x$, is calculated as

$\delta V_{i}=\frac{f_{i} U_{i} \Delta x}{c}$

where $c$ is the linear speed at which the belt moves. In Eq. (12), $\Delta x / c$ is equal to the time for the filter to move the distance $\Delta x$. The cumulative filtered volume per unit area, up to the element $i$, is calculated as the summation of the filtrate passing through each prior element. This is given as

$V_{i}=\sum_{j=1}^{i} \delta V_{j}=\sum_{j=1}^{i} \frac{f_{j} U_{j} \Delta x}{c}$

The flow rate per unit width through each filter element is calculated by multiplying the local velocity, $U$, by the open area per unit width, which is equal to the product of $\Delta x$ and $f$. The volumetric flow rate per unit width, is therefore given as

$\frac{Q_{i}}{w}=f_{i} U_{i} \Delta x$

The flow rate per unit width through the entire filter is calculated by summing the flow rate through over each element in the domain. This results in

$\frac{Q}{W}=\sum_{i=1}^{N} f_{i} U_{i} \Delta x$

Once the overall flow rate through the system is calculated, the head difference is updated, since the flow rate changes the value of $\Delta h_{\text {weir }}$. This process is repeated until the cumulative filtered volume per unit area for one filtration cycle and overall flow rate through the system converge. Convergence is defined as both quantities changing by less than $10^{-5}$ from one iteration to the next. Once the solution has converged, the cumulative filtered volume per unit area for the cycle can be used to calculate the removal efficiency using Eq. (7), fitted to experimental sieve test results.

To summarize, the overall process implemented in the filtration model is as follows:

1. Discretize filter domain into discrete elements.

2. Generate array of open area ratios, based on blockage due to support materials.

3. Initialize the head difference array, assuming $Q / w=0$.

4. Calculate the flow rate and cumulative filtered volume per unit area according to Eqs. (11)-(13).

5. Calculate total flow rate per unit width, according to Eq. (15).

6 . Update head difference array using calculated value of $Q / w$ and Eqs. (8)-(10).

7. Check if $V_{N}$ and $Q / w$ are converged. If yes, continue to next step. If no, return to step 4 .

8. Calculate removal efficiency using calculated value of $V_{N}$ and Eq. (7).

\subsection{Scaling cake resistance and effluent TSS with influent TSS concentration}

As mentioned, a benefit of splitting the mesh and cake resistances into separate terms is the ability to scale the cake resistance for varying influent TSS concentrations while leaving the mesh resistance as a function of velocity with constant resistance coefficients. TSS scaling is done by introducing a scaling factor, $\tau$, which is calculated by dividing the influent TSS concentration by the TSS concentration in the column test that has provided the data to the filtration process model. To account for the change in cake resistance due to the change in TSS, the filtered volume array is scaled by $\tau$. The hypothesis is that a higher TSS influent would require less volume to be filtered in order produce the same cake. It is assumed that this scaling is linear, i.e. that doubling TSS will halve the filtrate volume required to build a cake with the same resistance. This approximation will be tested in the results that are to be presented. The sieve test results are scaled in a similar manner, wherein the filtered volume in Eq. (7) is divided by $\tau$ and $C_{0}$ is multiplied by $\tau$.

\subsection{PID controller}

To control the upstream water level in a filtration unit, the filter speed is controlled dynamically. For the purposes of this modeling work, a PID controller is implemented. The governing equation for a PID controller is given as (Franklin et al., 2015)

$u(t)=k_{P} e(t)+k_{I} \int_{t_{0}}^{t} e(\tau) d \tau+k_{D} \frac{d e}{d t}$

where $u(t)$ is control signal, $k_{P}$ is the proportional gain, $k_{I}$ is the integral gain, $k_{D}$ is the derivative gain, and $e(t)$ is the control error. The control error is the difference between the process variable, $P V$, and the set point, $S P$, defined as

$e(t)=S P-P V(t)$

In a filtration unit, the process variable is the upstream water level. The upstream water level, when the system is operating dynamically, is calculated through a mass balance. Taking the control volume of interest to be the fluid on the upstream side of the filter, as shown in Fig. 3, a mass balance requires

$\Delta V=\left(Q_{\text {in }}-Q_{\text {out }}\right) \Delta t$

where $\Delta V$ is the change in volume contained on the upstream side of the filter, while $Q_{\text {in }}$ and $Q_{\text {out }}$ are the flow rates in and out of the 


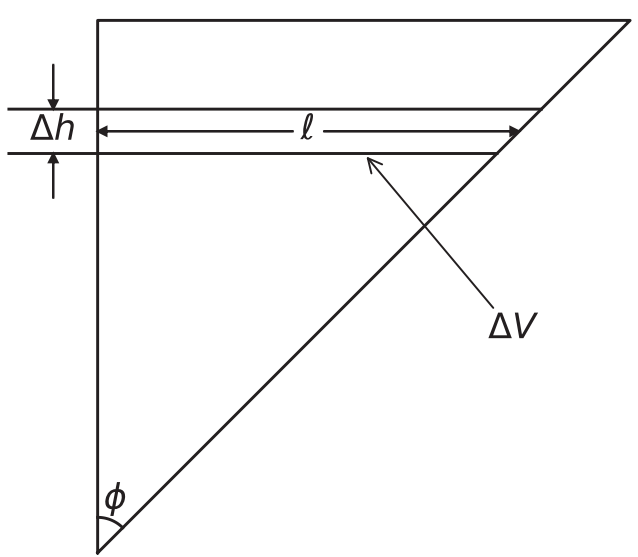

Fig. 3. Schematic diagram showing the geometry used for calculating the change in water level over a timestep of a simulation.

unit, respectively, and $\Delta t$ is the time step. Assuming the upstream water region to be triangular, it can be shown that

$\Delta V=\Delta h \ell w$

where $\Delta h$ is the change in water level, $l$ is the horizontal length of the fluid, and $w$ is the width of the filter. The fluid length, $l$, can be determined using the angle the filter makes with the vertical and the water height from the previous time step, shown as

$\ell=h_{\text {upstream }}^{i-1} \sin (\phi)$

The change in water level, based on Eqs. (18)-(20), is therefore

$\Delta h=\frac{\left(Q_{\text {in }}-Q_{\text {out }}\right) \Delta t}{h_{\text {upstream }}^{i-1} \sin (\phi) w}$

The updated water level is then found by adding the change in water level to the water level from the previous time step. The fact that the change in volume is calculated using a rectangular region is a first-order approximation which reduces the complexity of the solution. Provided that the timestep is small enough that the change in volume is small, the error induced by this approximation will be negligible.

\section{Results and discussion}

\subsection{Column test results}

Fig. 4 illustrates the variation of the water level as a function of time in a gravity drainage column test run using primary influent wastewater with a TSS of $373 \mathrm{mg} / \mathrm{L}$, obtained from a municipal WWTP. The rapid initial drop in water level results from filtration that is dominated by the mesh resistance, since a significant cake layer has not yet formed on the initially clean filter. As the cake layer builds, the rate of change of water level decreases as the cake layer leads to increased resistance to flow. Also shown in Fig. 4 is the result of fitting the double exponential function, given in Eq. (3), which shows satisfactory agreement as compared to the experimental data.

The cake resistance as a function of the cumulative filtered volume per unit area is calculated using the fitted column data shown in Fig. 4, along with Eqs. (5) and (6), and is shown in Fig. 5. This figure shows that the cake resistance reaches an asymptote at a filtered volume of around $0.42 \mathrm{~m}^{3} / \mathrm{m}^{2}$, which corresponds with a water level of approximately $0.3 \mathrm{~m}$, which occurs after $4.5 \mathrm{~s}$ of drainage. It can be seen that this point in time corresponds closely to the end of the transition region between the exponential functions, where cake resistance is completely dominant over mesh resistance. At this point, the flow rate is extremely slow, which explains the asymptotic behavior as it would take an extremely long time to build any more cake with such a slow rate of filtration. Column test results similar to those presented in this section are collected for each wastewater quality that will be tested using the filtration process model. Based on the column results, a table of filtration volume per unit area and cake resistance is generated for use within the process model.

\subsection{Sieve test results}

Fig. 6 shows results from a sieve test, where a range of volumes of municipal wastewater with a TSS concentration of $202 \mathrm{mg} / \mathrm{L}$ have been filtered. As the filtered volume increases, it can be seen that the effluent TSS concentration decreases, due to the formation of a larger cake layer on the filter. The result of fitting the exponential function given in Eq. (7) are also shown in Fig. 6, which shows close agreement between experimental results and the

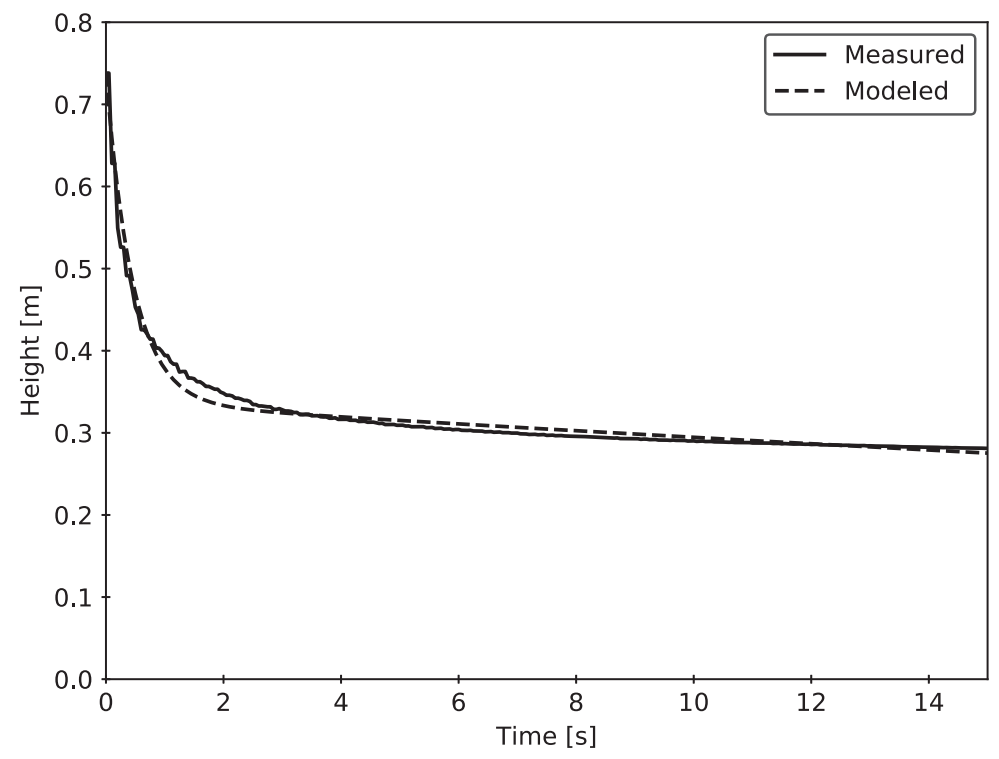

Fig. 4. Results for the water height as a function of time for a gravity drainage column test, compared with the fitted double-exponential function. 


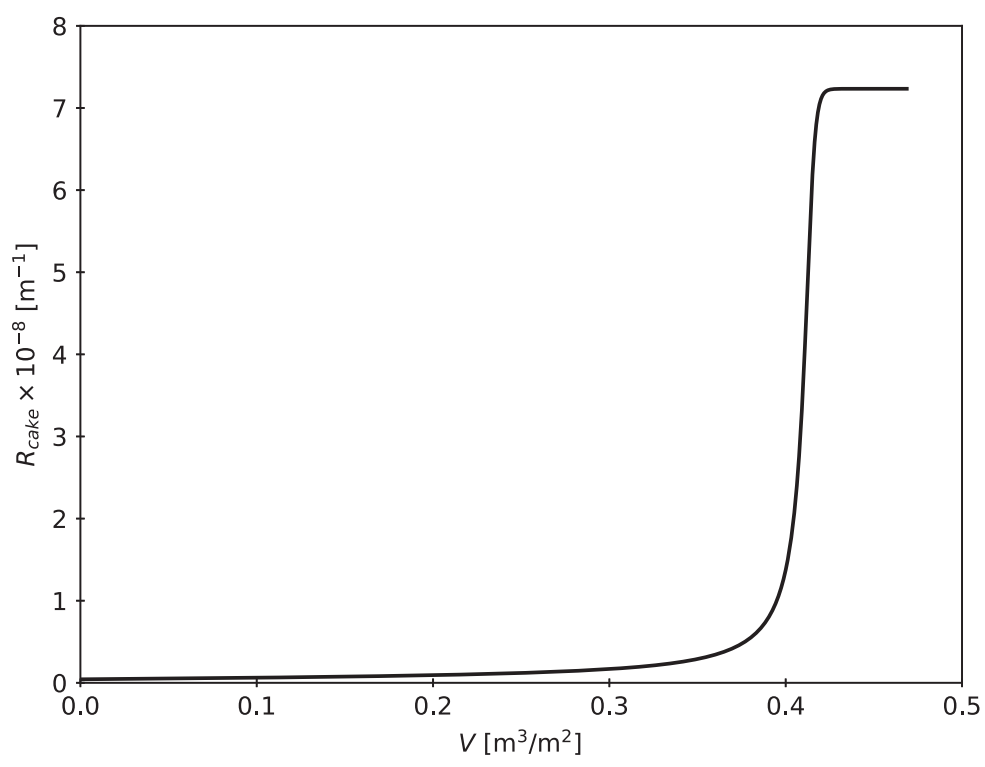

Fig. 5. Cake resistance as a function of filtered volume per unit area for a column test experiment.

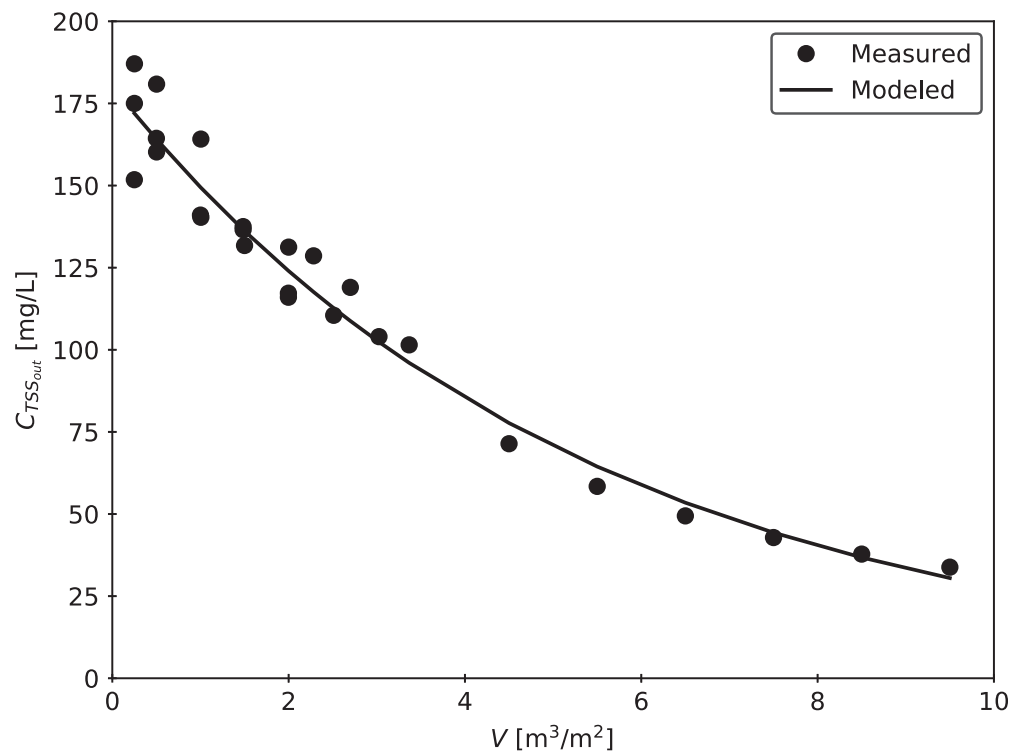

Fig. 6. Results for the effluent TSS concentration as a function of the filtered volume per unit area for a sieve test, compared to the fitted model.

model. As with the column test, the results of the fitted model coming from the sieve test are used as input into the filtration process model.

\subsection{Filtration process model results}

\subsubsection{Sizing curves}

The filtration process model allows for the prediction of both the hydraulic capacity, $Q$, and removal efficiency, $\eta$, based on the

Table 1

Specifications for the filtration units used to generate sizing curves.

\begin{tabular}{lccc}
\hline & $h_{\text {upstream }}[\mathrm{m}]$ & $h_{\text {weir }}[\mathrm{m}]$ & Belt angle $\left[{ }^{\circ}\right]$ \\
\hline Unit 1 & 0.3 & 0.1 & 30 \\
Unit 2 & 0.5 & 0.2 & 30 \\
Unit 3 & 0.7 & 0.3 & 30 \\
Unit 4 & 0.9 & 0.5 & 30 \\
\hline
\end{tabular}

specifications of the particular filtration unit and the model parameters coming from column and sieve test experiments for the particular wastewater under consideration. In this section, sizing curves are presented based on hypothetical dimensions and experimental parameters to illustrate the trends that can be observed. Table 1 gives the dimensions of the four units that are tested, which span the typical range of values for most commercial filtration units. For these tests, no structural blockage of the filter was assumed. The column test parameters used in this section are summarized in Table 2, denoted as Case 1 . The sieve test parameters were $C_{0}=220 \mathrm{mg} / \mathrm{L}$ and $\gamma=0.35 \mathrm{~m}^{2} / \mathrm{m}^{3}$. Although the parameters are arbitrary in this case, they represent typical magnitudes of values obtained for municipal wastewater in London, Canada.

Fig. 7a and b show the hydraulic capacity and removal efficiency sizing curves for the specifications given. It can be observed that the hydraulic capacity is higher for filtration units with larger dimensions. This is expected, since the filtration area is larger due to the longer filter, and the fact that there will generally be a larger 


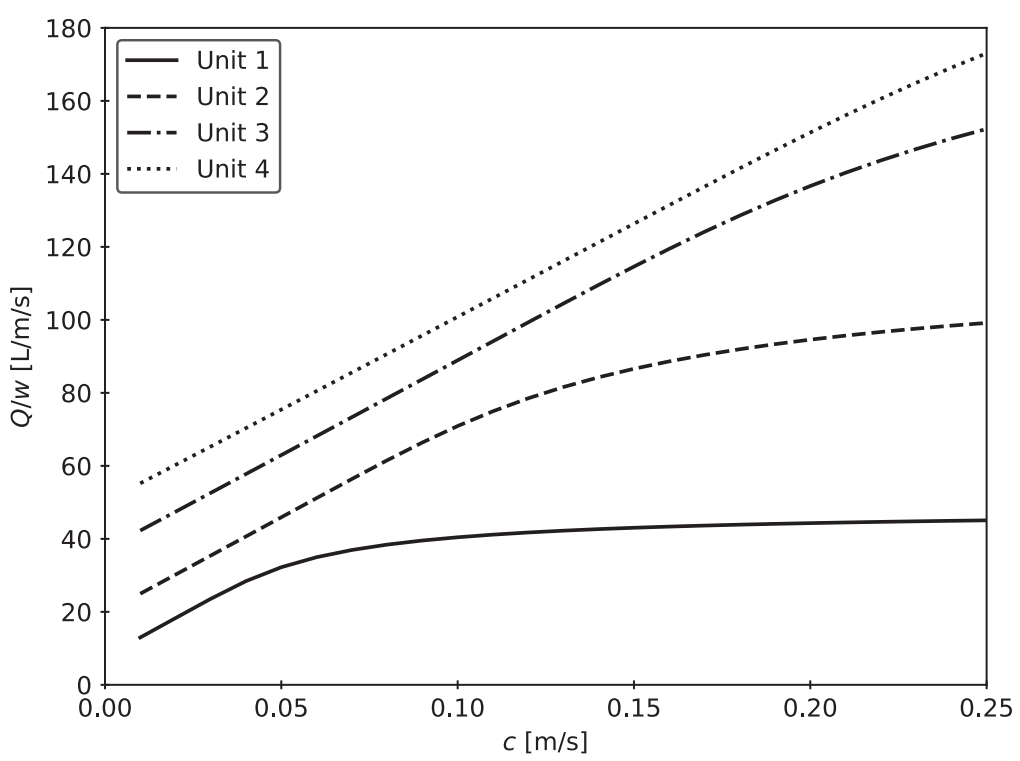

(a)

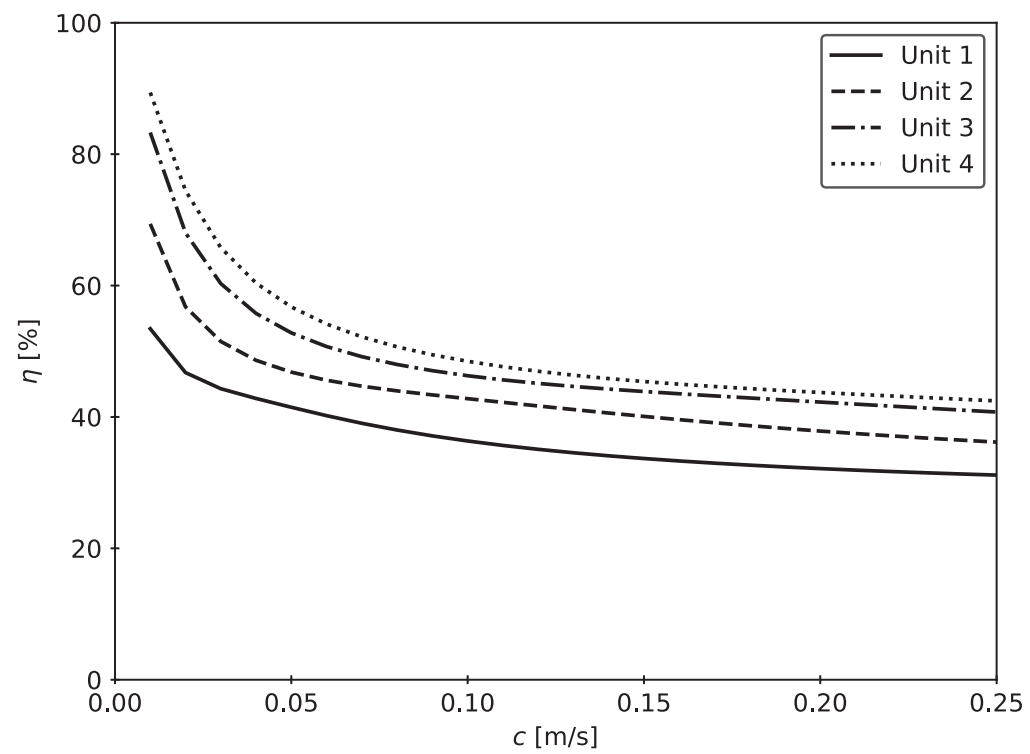

(b)

Fig. 7. Plots of (a) hydraulic capacity and (b) removal efficiency as a function of filter speed for filtration units with different dimensions.

head difference across the filter. The hydraulic capacity is seen to increase as a function of the filter speed. This can be explained on the basis that less cake is able to accumulate over the shorter filtration cycle, leading to an overall larger flow rate through the system. The consequence of the thinner cake layer can be seen by the fact that the removal efficiency decreases with filter speed. This highlights the trade off that must be considered between improving capacity while also attaining the required removal performance.

Further examination of Fig. 7a shows that there appears to be a maximum hydraulic capacity that can be attained, regardless of the filter speed. A clear asymptote can be seen for Units 1 and 2, while it appears that such a limit has not been reached for Units 3 and 4 within the speeds tested. This indicates that although each unit has a maximum capacity, that capacity occurs at a larger filter speed for larger units. It is concluded that this must be due to the increased head difference for larger units, since this is the only factor differing in the curves presented. There also appears to be a minimum removal efficiency that is attained regardless of the filter speed, but that this generally occurs at a lower filter speed than that for the maximum hydraulic capacity. From a design perspective, this could simplify the trade off between capacity and removal, since the worst case of removal is predicted fairly easily.

\subsubsection{TSS scaling results}

It is expected that the TSS concentration for a given column or sieve test will be different from the TSS at any given moment for an operating filter unit. Therefore, it is important to have the ability to 
scale the results to account for changing TSS. Fig. 8a and b show the effect of different influent TSS concentrations for Unit 2, described in Table 1, with the same model parameters specified as in the previous case. In this case, the TSS value of $300 \mathrm{mg} / \mathrm{L}$ is taken as the reference value for scaling. As the influent TSS concentration varies, it has a significant effect on both the resulting capacity and removal efficiency predictions. Increasing the influent TSS concentration reduces the capacity and increases the removal efficiency of the filtration unit, due to the effect of a more rapid cake layer growth. The opposite can be observed when the influent TSS concentration is reduced, caused by the reduction in cake layer growth.

Based on the results in Fig. 8, it appears that the hydraulic capacity is more sensitive to the influent TSS concentration, partic- ularly at higher filter speeds. This points to the need to control the filter speed, since a change in influent TSS could easily cause the filter unit to overflow, especially if the influent is provided at a constant rate. Consider a situation where the TSS increases from $300 \mathrm{mg} / \mathrm{L}$ to $900 \mathrm{mg} / \mathrm{L}$ and the influent is provided to the unit at a constant rate of $40 \mathrm{~L} / \mathrm{s}$ per unit width of filter. Fig. 8a indicates that the belt speed would need to increase from approximately 0.04 to $0.12 \mathrm{~m} / \mathrm{s}$ to maintain the same upstream water level. On the other hand, Fig. 8b shows that the removal efficiency would only change from around 49 to $44 \%$. To consider another way, if the unit is handling $40 \mathrm{~L} / \mathrm{s}$ per unit width of filter with a TSS of $300 \mathrm{mg} / \mathrm{L}$ and the TSS increased to $900 \mathrm{mg} / \mathrm{L}$, without changing the belt speed, there would be an overflow of approximately 13 $\mathrm{L} / \mathrm{s}$ per unit width of filter. Certainly, overflow must be avoided

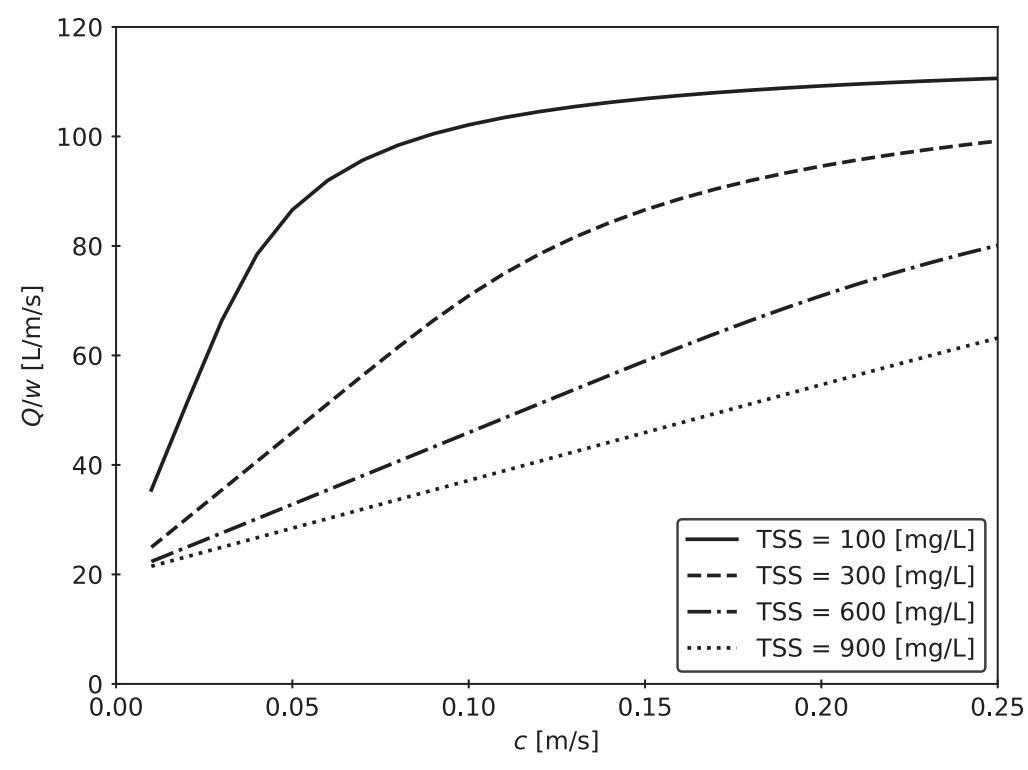

(a)

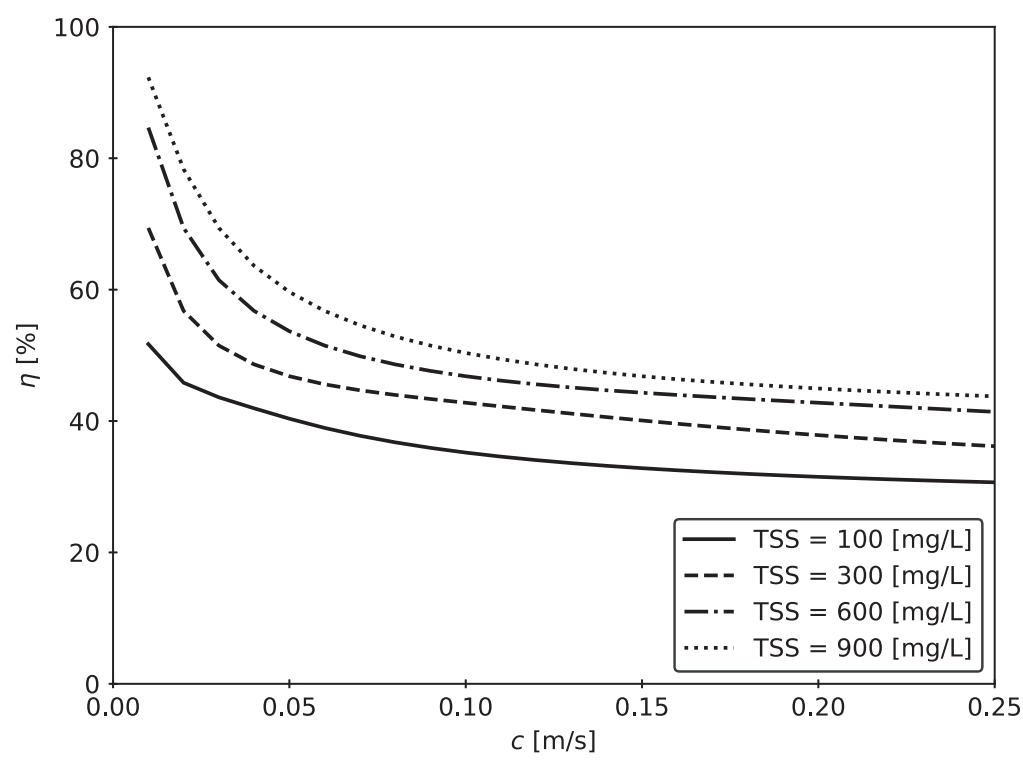

(b)

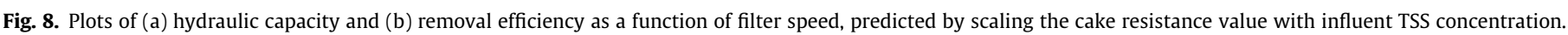


whenever possible, so a controller should be implemented to maintain the upstream water level while input variables such as influent TSS concentration and flow rate vary.

\subsubsection{PID controller results}

To test the implementation of the PID controller in the filtration process model, a test was conducted where an arbitrary initial filter speed and upstream water level were given as the initial condition. The flow rate into the unit was maintained as a constant value of $50 \mathrm{~L} / \mathrm{s}$ and the set point for the upstream water level was $0.45 \mathrm{~m}$. In this case, the proportional gain was $k_{P}=1$, the integral gain was $k_{I}=2$, the derivative gain was $k_{D}=0$, and the timestep was $\Delta t=0.5 \mathrm{~s}$. The derivative term in the PID controller was disabled in this, and all subsequent cases, due to the noise it induced into the solution. The column test parameters for this case are given in Table 2, denoted Case 2. These column test parameters were measured for a particular sample of primary influent wastewater at a municipal WWTP in London, Canada. Since the removal efficiency is not considered in these results, sieve test results are not required.

The results of this simulation are shown in Fig. 9, which shows the response in terms of the filter speed and the upstream water level. Immediately, the water level can be seen rising, as the reservoir is initially set to a level of $0.3 \mathrm{~m}$. Simultaneously, the filter speed is dropping, since the water level is below its set point. It should be noted that the filter speed was limited to a minimum value of $0.015 \mathrm{~m} / \mathrm{s}$, which is reached quickly. After some time, the set point for the upstream water level is exceeded, and the filter begins increasing its speed to bring this towards the set point. Eventually, the water level reaches its set point and the filter speed reaches a steady value, without any significant oscillations about its final value. The results of this test are quite satisfactory and indicate that the filter unit can be controlled effectively in this manner.

To study the effects of variable influent TSS, using the scaling concept described previously, a case similar to the previous was set up with an influent TSS profile in the shape of a triangular wave. The minimum TSS value was $275 \mathrm{mg} / \mathrm{L}$ and the maximum was $525 \mathrm{mg} / \mathrm{L}$. The wavelength of the TSS profile was $500 \mathrm{~s}$. A constant inlet flow rate of $50 \mathrm{~L} / \mathrm{s}$ was specified with a $0.45 \mathrm{~m}$ upstream water level set point. The results of this test are shown in Fig. 10. The results show that the filter speed correctly tracks the influent
TSS concentration in a triangular wave pattern. As the influent TSS concentration decreases linearly, the filter speed also decreases linearly to build a larger cake that prevents the water level from dropping from the set point. Likewise, as the influent TSS concentration increases linearly, the filter speed also increases linearly to reduce the cake thickness and prevent accumulation of liquid upstream of the filter. In the results shown, the upstream water level quickly reaches its set point and does not vary significantly from the value through the simulation. These results are promising, enabling the model to be validated with full-scale filtration data.

\subsubsection{Validation results}

The filtration model is validated by taking unit dimensions and operating parameters (upstream water level, filter speed, influent TSS concentration, and blockage parameters) from a full-scale pilot installation as model inputs, and comparing the predicted flow rate from the model to that of the pilot. The first test that is done is used to test the sensitivity of the model predictions to the inputs coming from the column test, which is also compared with $4 \mathrm{~h}$ of measured data. The second test, considers calibration of the model using the most sensitive model parameter, and comparing with $12.5 \mathrm{~h}$ of experimentally measured data. In both cases, the influent TSS varies in time, so the TSS scaling method described previously was used to take into account these variations in the simulations.

The sensitivity analysis was done on the three sizing parameters coming from the column test $(A, \alpha$, and $\beta)$ to determine which has the greatest effect on the output. Each parameter was varied by $\pm 10 \%$ from the baseline parameters (listed in Table 2, Case 3 ) that were measured from a column test and the resulting flow rates were compared. The upstream water level, filter speed, and influent TSS concentrations used for the sensitivity study were taken from measured pilot data. It was found that varying the parameter $A$ had the greatest effect on filtration model performance, as seen in Fig. 11. In this figure, the shaded area represents the limits of the model prediction when the parameters are varied by $10 \%$ in both the positive and negative direction. As noted, $A$ has the greatest impact on the model prediction, followed by $\alpha$, which has an effect on the model prediction, but to a much lesser extent than $A$. The parameter $\beta$ does not have a noticeable effect on the solution, when varied by $\pm 10 \%$. This plot also shows experimentally measured data from a full scale filter. Overall, the model does predict the correct trends, but appears to be more sensitive to

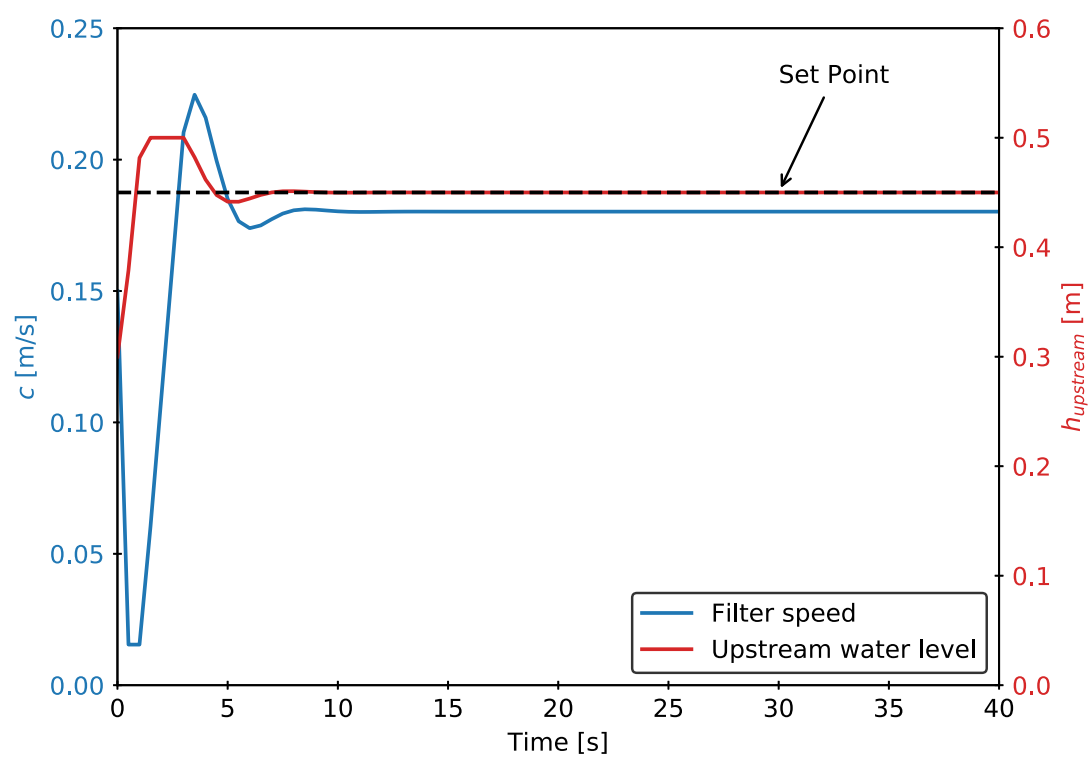

Fig. 9. Response of filter speed due to PID controller with a set point for upstream water level, under steady inputs and an arbitrary initial condition. 


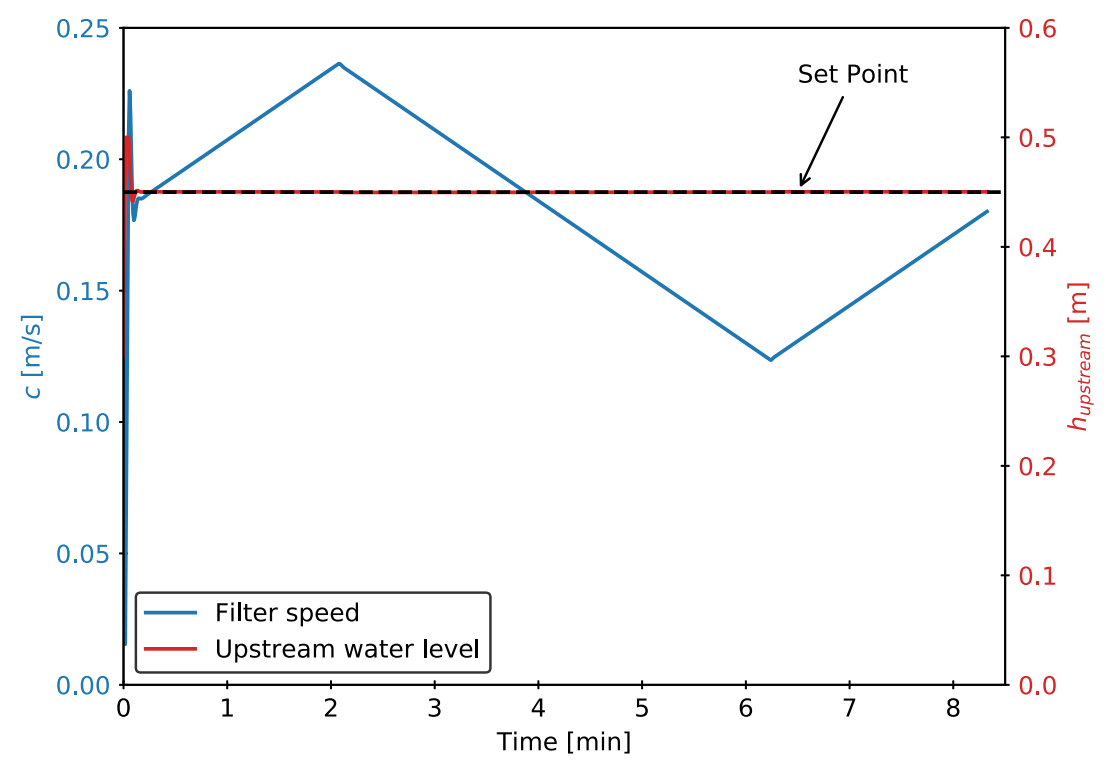

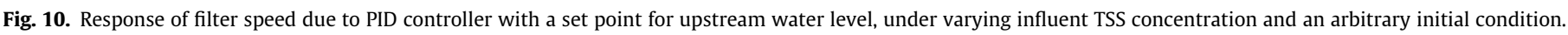

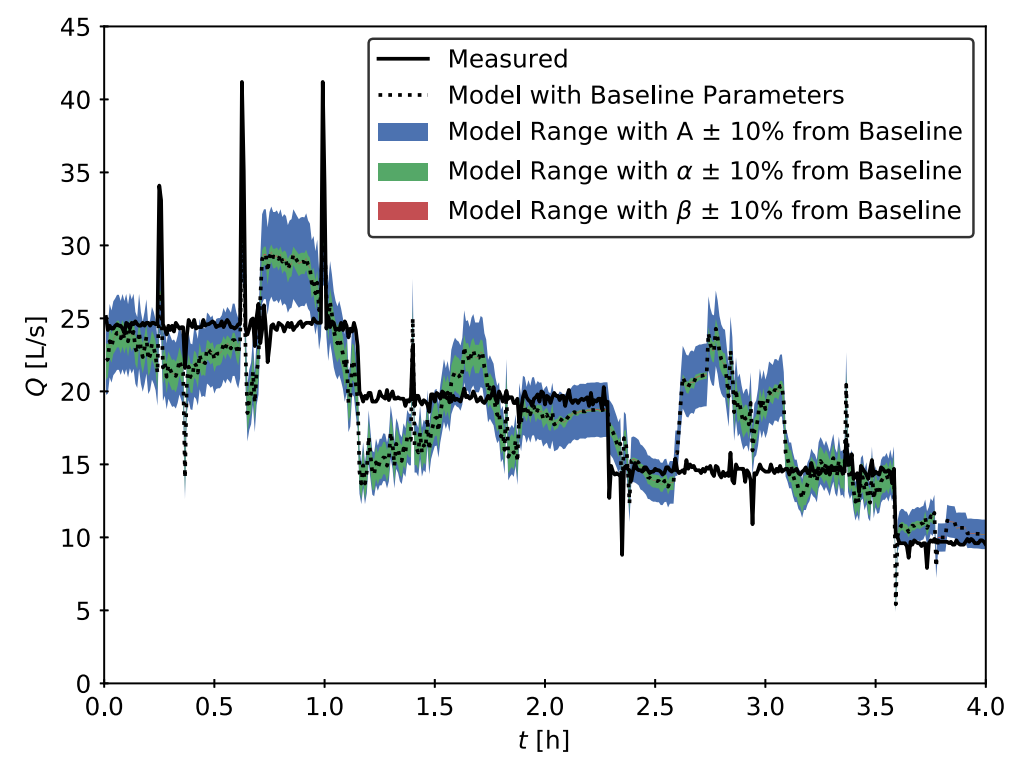

Fig. 11. Sensitivity analysis carried out by varying each model parameter by $\pm 10 \%$, in comparison to experimental measurements.

the input data, which results in a more fluctuating signal for flow rate.

The second validation case uses the column test parameters listed in Table 2, Case 4. The influent TSS concentration from the pilot measurements ranged from 280 to $686 \mathrm{mg} / \mathrm{L}$ with a mean value of $442 \mathrm{mg} / \mathrm{L}$. A comparison of the predicted and measured flow rates are shown in Fig. 12. It can be seen that there is some discrepancy between the two flow rates, when the column parameters are used directly. Based on the sensitivity analysis, which revealed that the parameter $A$ has the greatest effect on the flow rate prediction, this parameter was calibrated using a numerical optimization procedure to minimize the error between the model prediction and the experiment, over the full $12.5 \mathrm{~h}$ of measurement data. This result is also shown in Fig. 12, which shows that the calibration process does indeed improve the match with the experiments. In both modeled cases, there are additional fluctuations in flow rate as compared to the experimental measurements, which used a pumped flow and it therefore more consistent between each set point for flow. Part of this can be explained on the basis that the TSS values used for scaling are measured optically at a regular time frequency and calibrated to a select number of samples that were analyzed gravimetrically. It is noted that there are some fluctuations in the TSS signal, which may not be representative of reality, and may be the cause of some of the additional fluctuations in the model predictions.

It is clear that the original column test parameters lead to an under-prediction of the flow rate, while the calibrated model gives much better overall agreement. While the value of $A$ obtained from the column test was $A=0.272$, the calibrated value was $A=0.408$. It is hypothesized that the capacity is under-predicted in this case due to a destruction of the cake layer in the full-scale system, caused by the turbulent flow entering the unit as well as recirculation zones that would form in any cavity with a moving surface. The result of cake erosion would be a lower cake resistance, and 


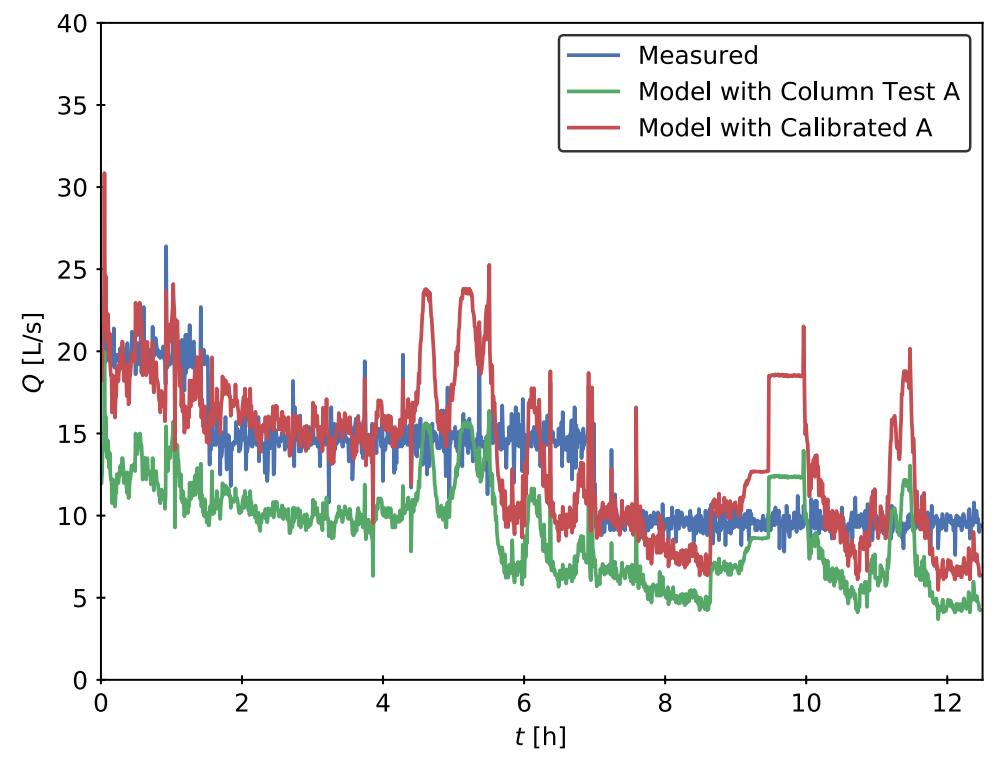

Fig. 12. Optimized column test parameter A compared to regular data against pilot data.

Table 2

Column test parameters used in the present study.

\begin{tabular}{|c|c|c|c|c|c|}
\hline Case & $h_{0}[\mathrm{~m}]$ & $A[\mathrm{~m}]$ & $\alpha\left[\mathrm{s}^{-1}\right]$ & $\beta\left[\mathrm{s}^{-1}\right]$ & $C_{T^{\prime S S_{\text {ref }}}}[\mathrm{mg} / \mathrm{L}]$ \\
\hline Case 1 & 1 & 0.6 & 1 & 0.1 & 300 \\
\hline Case 2 & 0.936 & 0.227 & 3.03 & 0.002 & $\mathrm{~N} / \mathrm{A}$ \\
\hline Case 3 & 0.669 & 0.259 & 2.25 & 0.005 & 693 \\
\hline Case 4 & 0.795 & 0.272 & 1.42 & 0.008 & 353 \\
\hline
\end{tabular}

therefore a higher capacity would be predicted as compared to the ideal case of the column test would not suffer from cake erosion. In order to model cake erosion, information about the fluid shear stresses on the cake would be required. This could be accomplished by coupling the proposed model with a computational fluid dynamics simulation for the flow field (DeGroot et al., 2015), although this would require a better understanding of the relationship between fluid shear and changes in the cake layer. Nevertheless, the results shown here are very promising and show that the proposed one dimensional process model, including the concept of TSS scaling, is capable of accurately predicting the performance of filtration units with continuously moving fine mesh filters.

\section{Summary}

In this study, an experimentally validated, one-dimensional model for continuously moving fine mesh filters was developed to predict their hydraulic capacity and removal efficiency. Cake formation along the filter was modeled based on results from gravity drainage column tests and a mathematical model to extract the cake resistance as a function of filtered volume per unit area from column height versus time data. The removal efficiency was determined by correlating the removal efficiency of a sieve test with the filtered volume per unit area, which was linked to the filtration process model variables. A scaling process was introduced to allow for results to be obtained for influent TSS concentrations that are different from those testing in the column experiments. Furthermore, a PID controller was implemented into the model. Results were presented to show the main parameter to which the predictions are sensitive, leading to a calibration procedure. Finally, comparisons have been made with full-scale filtration data, which show that the model is successful in predicting the performance of continuously moving fine mesh filters.

\section{Acknowledgements}

Funding: This work was supported by the Natural Science and Engineering Research Council (NSERC) [CRDPJ 488704-15, 2016] and [EGP 496723-16, 2016].

\section{Appendix A}

A summary of the column test parameters used in the process model simulations is presented in Table 2 .

\section{References}

Bai, R., Tien, C., 2005. Further work on cake filtration analysis. Chem. Eng. Sci. 60 (2), 301-313.

Behera, C.R., Santoro, D., Gernaey, K.V., Sin, G., 2018. Organic carbon recovery modeling for a rotating belt filter and its impact assessment on a plant-wide scale. Chem. Eng. J. 334, 1965-1976.

DeGroot, C.T., Sheikholeslamzadeh, E., Soleymani, A., Santoro, D., Batstone, D.J., Rosso, D., 2015. Understanding primary treatment performance and carbon diversion potential of rotating belt filters using computational fluid dynamics. In: Proceedings of the Water Environment Federation, WEFTEC 2015. Water Environment Federation, pp. 1249-1262.

DeGroot, C.T., Sheikholeslamzadeh, E., Santoro, D., Sarathy, S., Lyng, T.-O., Wen, Y., Daynouri-Pancio, F., Rosso, D., 2016. Dynamic modeling of rotating belt filters enables design exploration and advanced sizing with varying influent conditions. In: Proceedings of the Water Environment Federation, WEFTEC 2016. Water Environment Federation, pp. 1158-1168.

Franchi, A., Santoro, D., 2015. Current status of the rotating belt filtration (RBF) technology for municipal wastewater treatment. Water Pract. Technol. 10 (2) 319-327.

Franklin, G.F., Powell, J.D., Emami-Naeini, A., 2015. Feedback Control of Dynamic Systems. Pearson. 
Ho, C.-C., Zydney, A.L., 2000. A combined pore blockage and cake filtration model for protein fouling during microfiltration. J. Colloid Interface Sci. 232 (2), 389-399.

Osterroth, Sebastian, Preston, Caleb, Markicevic, Bojan, Iliev, Oleg, Hurwitz, Mark, 2016. The permeability prediction of beds of poly-disperse spheres with applicability to the cake filtration. Sep. Purif. Technol. 165, 114-122.

Paulsrud, B., Rusten, B., Aas, B., 2014. Increasing the sludge energy potential of wastewater treatment plants by introducing fine mesh sieves for primary treatment. Water Sci. Technol. 69 (3), 560-565.

Rusten, B., Odegaard, H., 2006. Evaluation and testing of fine mesh sieve technologies for primary treatment of municipal wastewater. Water Sci. Technol. 54 (10), 31-38.

Rusten, B., Rathnaweera, S.S., Rismyhr, E., Sahu, A.K., Ntiako, J.., 2017. Water Sci. Technol. 75 (11), 2598-2606.

Sherratt, A., DeGroot, C.T., Straatman, A.G., Santoro, D., 2018. A numerical approach for determining the resistance of fine mesh filters. Trans. CSME. https://doi.org 10.1139/tcsme-2018-0071.

Tchobanoglous, G., Stensel, H.D., Tsuchihashi, R., Burton, F., 2014. Wastewater Engineering: Treatment and Resource Recovery. McGraw-Hill, New York.

Teklehaimanot, G.Z., Kamika, I., Coetzee, M.A.A., Momba, M.N.B., 2015. Population growth and its impact on the design capacity and performance of the wastewater treatment plants in Sedibeng and Soshanguve, South Africa. Environ. Manage. 56 (4), 984-997.

Teoh, S.-K., Tan, R.B.H., Tien, C., 2006. Analysis of cake filtration data - a critical assessment of conventional filtration theory. AIChE J. 52 (10), 3427-3442.

Tien, C., 2002. Cake filtration research - a personal view. Powder Technol. 127 (1), $1-8$.

Tien, C., 2012. Principles of Filtration. Elsevier, Oxford, U.K.

Tien, C., Bai, R., 2003. An assessment of the conventional cake filtration theory. Chem. Eng. Sci. 58 (7), 1323-1336.

Tien, Chi, Ramarao, Bandaru V., 2008. On the analysis of dead-end filtration of microbial suspensions. J. Membr. Sci. 319 (1-2), 10-13.

Tien, C., Ramarao, B.V., 2011. Revisiting the laws of filtration: an assessment of their use in identifying particle retention mechanisms in filtration. J. Membr. Sci. 383 (1-2), 17-25.

Tien, C., Ramarao, B.V., Yasarla, R., 2014. A blocking model of membrane filtration. Chem. Eng. Sci. 111, 421-431.

Vafai, K., Tien, C.L., 1981. Boundary and inertia effects on flow and heat transfer in porous media. Int. J. Heat Mass Transf. 24 (2), 195-203.

Ward, J C, 1964. Turbulent flow in porous media. J. Hydraulics Div. Proc. Am. Soc. Civil Eng. 90, 1-12. 